Original Article

\title{
Effects of body awareness training on mild visuospatial neglect in patients with acute stroke: a pilot randomized controlled trial
}

\author{
Dae-Hyouk Bang, PT, MSc ${ }^{1)}$, Hyun-Jeong Noh, PT, MSc ${ }^{1)}$, Hyuk-Shin Cho, PT, $\mathrm{PhD}^{2)^{*}}$ \\ 1) Department of Physical Therapy, Graduate School of Daejeon University, Republic of Korea \\ 2) Department of Physical Therapy, Wonkwang Health Science University: 514 Sinyong-dong, Iksan-si, \\ Jeollabuk-do 570-750, Republic of Korea
}

\begin{abstract}
Purpose] This study aimed to investigate the effects of body awareness training (BAT) on mild visuospatial neglect in patients following acute stroke. [Subjects] The subjects were 12 stroke patients randomly assigned to either the experimental group $\left(n_{1}=6\right)$ or control group $\left(n_{2}=6\right)$. [Methods] The experimental group underwent BAT for 15 minutes and then task-oriented training for 30 minutes a day, five times a week for three weeks. The control group underwent task-oriented training for 30 minutes a day, five times a week for three weeks. Assessments were made using the Motor-free Visual Perception Test (MVPT), Line Bisection Test (LBT), and modified Barthel index (MBI). [Results] Following the interventions, the experimental group showed a significant change in MVPT, LBT, and MBI scores. [Conclusion] The results of this study suggest the feasibility and suitability of BAT with taskoriented training for mild visuospatial neglect in patients with acute stroke.

Key words: Body awareness training, Neglect, Stroke
\end{abstract}

(This article was submitted Oct. 30, 2014, and was accepted Dec. 11, 2014)

\section{INTRODUCTION}

Visuospatial neglect is caused by hemorrhage or infarction of the cerebral cortex, and is defined as the failure of attending to, exploring, and acting upon the contralesional side of space $^{1)}$. Visuospatial neglect is considered a barrier to improvement in functional ability and motor recovery after stroke ${ }^{2}$. Although various strategies have been used to reduce the symptoms of visuospatial neglect, they are impractical as a basis for rehabilitation ${ }^{3)}$.

Task-oriented training was suggested to be an effective method for improving the performance of activities of daily living (ADLs) and reducing the symptoms of visuospatial neglect ${ }^{4}$. The task-oriented approach involves using the paretic side, with repetitive practice of daily tasks ${ }^{5}$. The task-oriented approach is reported to have reduced the symptoms of visuospatial neglect by improving motor-sensory processes and awareness of the paretic side ${ }^{5}$.

Body awareness training (BAT) is a method for improving dynamic balance and postural stability. BAT is composed of simple repetitive movements within stability limits ${ }^{6)}$. A main component of BAT is making the person conscious of their movements ${ }^{7)}$. In other words, BAT involves an awareness of

*Corresponding author. Hyuk-Shin Cho (E-mail: hscho90@ hanmail.net)

C2015 The Society of Physical Therapy Science. Published by IPEC Inc. This is an open-access article distributed under the terms of the Creative Commons Attribution Non-Commercial No Derivatives (by-ncnd) License $<$ http://creativecommons.org/licenses/by-nc-nd/3.0/> one's body and reflection upon how the body feels during movement. Movements are performed in various positions to find a center line of the body. BAT targets include postural control, balance, free breathing, and coordination ${ }^{8}$. Various studies ${ }^{6-8)}$ have reported that BAT has positive effects in improving function.

Unfortunately, there are no reported studies of BAT being used in stroke patients with mild visuospatial neglect. Therefore, the purpose of this study was to investigate the effects of BAT in acute stroke patients with mild visuospatial neglect using the Motor-free Visual Perception test (MVPT), Line Bisection Test (LBT), and modified Barthel index (MBI).

\section{SUBJECTS AND METHODS}

The subjects were 12 poststroke individuals admitted to a rehabilitation center at a university hospital in the Republic of Korea. They were randomized into two groups by a person not involved in the study: the experimental group underwent BAT before task-oriented training, with the BAT being performed for 15 minutes; the control group performed task-oriented training only. The inclusion criteria for the LBT was based on patients who deviated $\geq 15 \%$ to the right from the center ${ }^{9)}$. The exclusion criteria were (1) severe cognitive impairment making them unable to understand the instructions given by a therapist; (2) contraindications to the interventions, and (3) unstable medical or neurological conditions.

Participation in the study was voluntary, and the subjects fully understood the contents of the study. Written informed 
consent, after following an explanation of the study purpose and the experimental method and processes, was obtained from all patients. The study was approved by the Daejeon University Institutional Review Board.

The MVPT $^{10}$ ) is a 36-item multiplechoice test that evaluates visuospatial neglect.

The LBT was performed using the method conceived by Schenkenberg et $\mathrm{al}^{11)}$. Twenty lines were drawn on A4 white paper parallel to the long axis. Eighteen of these lines were organized into three sets of six.

The $\mathrm{MBI}^{12)}$ comprises 10 items: dependent or independent for feeding, bathing, grooming or dressing; toilet use; mobility on level surface (immobile, use of wheelchair, walk with help, or independent); and bowels and bladder continent or incontinent.

Twelve people fulfilled the criteria and voluntarily agreed to participate in this study. The participants were randomly assigned into an experimental group $\left(\mathrm{n}_{1}=6\right)$ or control group $\left(\mathrm{n}_{2}=6\right)$. The interventions comprised three weeks of inpatient treatment. Participants in the experimental group underwent the BAT using the method suggested by Lindvall et $\mathrm{al}^{8)}$. The subjects were barefoot to enable contact with the floor during training. The intention was that participants would experience how the movement felt in their body, and how they could integrate the movements. Movements were performed in a sitting and standing position. In the sitting, a pillow wedge was used to ensure the ideal alignment, and the participants were not allowed to lean on the backrest. The participants were asked to be aware of the changes of tension in their bodies. The stability limits were experienced by shifting the body weight forward, backward, and to the left, and right sides. In the standing, the center line was perturbed by twisting around the center line and gently moving the arms.

Both groups underwent the task-oriented training for 30 minutes a day, five times a week for three weeks. The training comprised three weeks of inpatient treatment. The four tasks incorporated: (1) sitting alone at a table and correcting the body alignment, (2) reaching in different directions for objects located beyond arm's length using the non-paretic side, (3) reaching in different directions for objects located beyond arm's length using the paretic side, (4) bilateral reaching tasks such as throwing a ball, lifting a box, and putting on a ring.

Descriptive statistics were used to summarize the base- line data. Categorical variables (gender, side of stroke) were compared between groups with Fisher's exact test. Comparisons of baseline characteristics (age, weight, height, time after stroke, MVPT, LBT, and MBI scores) between the groups were performed using the Mann-Whitney U-test. Comparisons of pre- and post-test values within each group were performed using the Wilcoxon signed-rank test, and comparisons of post-test values between the groups were performed using the Mann-Whitney U-test. The significance level was set at $\mathrm{p}<0.05$.

\section{RESULTS}

All patients completed the interventions and assessments. There were no significant differences in gender, age, weight, height, and duration since onset between the groups (Table 1). Differences in MVPT, LBT, and MBI scores are presented in Table 2. After the interventions, both groups showed significant differences in MVPT, LBT, and MBI scores ( $\mathrm{p}<$ $0.05)$. There were significant differences after intervention in the MVPT $(\mathrm{z}=-2.59, \mathrm{p}=0.01)$, LBT $(\mathrm{z}=-2.25, \mathrm{p}=$ $0.03)$, and MBI $(z=-2.89, p=0.01)$ scores between the groups.

\section{DISCUSSION}

This study was conducted to evaluate the effects of BAT on mild visuospatial neglect following an acute stroke. The results of this study revealed that the BAT group showed

Table 1. General characteristics of subjects

\begin{tabular}{lcc}
\hline & $\begin{array}{c}\text { Experimental } \\
\text { group }\left(\mathrm{n}_{1}=6\right)\end{array}$ & $\begin{array}{c}\text { Control group } \\
\left(\mathrm{n}_{2}=6\right)\end{array}$ \\
\hline Gender & & \\
Male/female & $3 / 3$ & $2 / 4$ \\
Paretic side & & \\
Right/left & $0 / 6$ & $0 / 6$ \\
Age (years) & $62.8 \pm 8.4$ & $63.1 \pm 9.2$ \\
Weight (kg) & $65.3 \pm 4.8$ & $64.0 \pm 5.9$ \\
Height (cm) & $164.3 \pm 6.2$ & $163.7 \pm 4.5$ \\
Duration (days) & $18.7 \pm 3.8$ & $19.3 \pm 5.7$ \\
\hline
\end{tabular}

*Mean \pm SD

Table 2. Descriptive measurements

\begin{tabular}{llrrr}
\hline & \multicolumn{2}{c}{ Experimental group $\left(\mathrm{n}_{1}=6\right)$} & \multicolumn{2}{c}{ Control group $\left(\mathrm{n}_{2}=6\right)$} \\
\hline MVPT & \multicolumn{1}{c}{ Before } & \multicolumn{1}{c}{ After } & Before & \multicolumn{1}{c}{ After } \\
LBT & $18.0 \pm 1.4^{\mathrm{a}}$ & $32.0 \pm 2.6^{*+}$ & $18.0 \pm 1.3$ & $26.3 \pm 1.2^{*}$ \\
MBI & $10.6 \pm 1.6$ & $5.6 \pm 0.5^{*+}$ & $10.2 \pm 1.4$ & $6.4 \pm 0.6^{*}$ \\
\hline
\end{tabular}

${ }^{\mathrm{a}}$ Means $\pm \mathrm{SD}$

*Significant difference within group. ${ }^{+}$Significant difference between groups.

MVPT: Motor-free Perception Test; LBT: Line Bisection Test; MBI: modified Barthel index. The pre- and post-test assessments were performed before and after (after 3 weeks) the interventions, respectively.

The significance level was set at $\mathrm{p}<0.05$ for differences between the groups. 
a more significant improvement than the control group in MVPT, LBT, and MBI results. Task-oriented training effectively reduced the symptoms of visuospatial neglect in both groups, and the additional effects of BAT suggest that it would be an efficacious method for treating the symptoms of visuospatial neglect patients.

There have been no previous reports regarding the improvement of symptoms of visuospatial neglect following BAT. To our knowledge, this pilot randomized controlled trial is the first study to demonstrate a potentially beneficial effect of BAT on mild visuospatial neglect in acute stroke patients.

Visuospatial neglect may be caused by a disturbance of the balance of both hemispheres after unilateral cortical lesions. Koch et al. ${ }^{13)}$ reported that the hyperexcitability of the left posterior parietal cortex, resulting in left neglect, is frequently seen after development of a right hemispheric lesion.

In neglect patients, more intensive training is often recommended in order to see changes in performance and cognition ${ }^{14)}$. The choice of five days a week for the interventions was based on practical reasons. In a study by Gyllensten et al. ${ }^{15)}$, participants undergoing interventions improved their body awareness, attitudes toward their body, and selfefficacy. Our results are similar to the above results. In our study, the experimental group showed greater improvements in the MBI than the control group $(\mathrm{p}<0.05)$. Improvement of MBI has a positive impact in stroke patients. For independent living, stroke patients have to be able to improve their functional performance of ADLs. We thought that our results indicated an improved awareness of the body.

There are multiple factors in addition to visuospatial neglect that affect the ability to carry out ADLs, including improvements in balance, motor function, and cognition. Therefore, improvement in the MBI could be due to improvements in these factors. Future study is needed to assess functional gains in activities according to improvements in these factors in mild visuospatial neglect patients.

The results of this study indicate that BAT reduced the symptoms of visuospatial neglect and suggest the applicability of BAT for clinical rehabilitation. Reducing neglect symptoms in stroke patients increases the opportunities for improving function and independent living.

\section{ACKNOWLEDGEMENT}

This work was supported by the Wonkwang Health Science University Research Fund (2015).

\section{REFERENCES}

1) Chokron S, Dupierrix E, Tabert M, et al.: Experimental remission of unilateral spatial neglect. Neuropsychologia, 2007, 45: 3127-3148. [Medline] [CrossRef]

2) Song BK, Chung SM, Hwang BY: The effect of somatosensory training focused on the hand on hand function, postural control and ADL of stroke patient with unilateral spatial neglect and sensorimotor deficit. J Phys Ther Sci, 2013, 25: 297-300. [CrossRef]

3) Fierro B, Brighina F, Bisiach E: Improving neglect by TMS. Behav Neurol, 2006, 17: 169-176. [Medline] [CrossRef]

4) Toglia J, Cermak SA: Dynamic assessment and prediction of learning potential in clients with unilateral neglect. Am J Occup Ther, 2009, 63: 569-579. [Medline] [CrossRef]

5) Eskes GA, Butler B: Using limb movements to improve spatial neglect: the role of functional electrical stimulation. Restor Neurol Neurosci, 2006, 24: 385-398. [Medline]

6) Eriksson EM, Möller IE, Söderberg RH, et al.: Body awareness therapy: a new strategy for relief of symptoms in irritable bowel syndrome patients. World J Gastroenterol, 2007, 13: 3206-3214. [Medline]

7) Hedlund L, Gyllensten AL: The experiences of basic body awareness therapy in patients with schizophrenia. J Bodyw Mov Ther, 2010, 14: 245-254. [Medline] [CrossRef]

8) Lindvall MA, Forsberg A: Body awareness therapy in persons with stroke: a pilot randomized controlled trial. Clin Rehabil, 2014, 28: 1180-1188. [Medline] [CrossRef]

9) Rossetti Y, Rode G, Pisella L, et al.: Prism adaptation to a rightward optical deviation rehabilitates left hemispatial neglect. Nature, 1998, 395: 166-169. [Medline] [CrossRef]

10) Lee SW, Shin DC, Song CH: The effects of visual feedback training on sitting balance ability and visual perception of patients with chronic stroke. $\mathrm{J}$ Phys Ther Sci, 2013, 25: 635-639. [Medline] [CrossRef]

11) Schenkenberg T, Bradford DC, Ajax ET: Line bisection and unilateral visual neglect in patients with neurologic impairment. Neurology, 1980, 30: 509-517. [Medline] [CrossRef]

12) Nazzal M, Sa'adah MA, Al-Ansari D, et al.: Stroke rehabilitation: application and analysis of the modified Barthel index in an Arab community. Disabil Rehabil, 2001, 23: 36-42. [Medline] [CrossRef]

13) Koch G, Oliveri M, Cheeran B, et al.: Hyperexcitability of parietal-motor functional connections in the intact left-hemisphere of patients with neglect. Brain, 2008, 131: 3147-3155. [Medline] [CrossRef]

14) Morioka S, Matsuo A, Abe M, et al.: Body image of the unilateral spatial neglect patient with self-portratit drawing. J Phys Ther Sci, 2005, 17: 39-42. [CrossRef]

15) Gyllensten AL, Hansson L, Ekdahl C: Outcome of basic body awareness therapy. A randomized controlled study if patients in psychiatric outpatient care. Adv Physiother, 2003, 5: 179-190. [CrossRef] 